\title{
APPLICATION OF ARTIFICIAL NEURAL NETWORK IN THE EFFICIENT CONTROL OF THREE-PHASE INDUCTION MOTOR
}

\author{
Arineu F. Santos, Francisco A. S. Neves, Ronaldo R. B. Aquino, Marcelo C. Cavalcanti \\ Federal University of Pernambuco (UFPE) - DEE) \\ Recife - Brazil \\ arineu.santos@ufpe.br, fneves@ufpe.br,rrba@ufpe.br, marcelo.cavalcanti@ufpe.br
}

\begin{abstract}
This work presents a method for increasing the efficiency of three-phase induction motor drives over the entire operation range. The direct field oriented control of induction motors, including the effects of magnetic saturation is used. The magnetic saturation effect in the machine is modeled by the non-linear magnetization curve of the iron core. Artificial neural networks are used to predict the optimum reference rotor flux to be used in the vector control. Details about the chosen neural networks are given. Simulation and experimental results are presented and the motor losses reduction during different load conditions is evaluated.
\end{abstract}

Keywords - Artificial Neural Network, Energy Conservation, Induction Motor Drives.

\section{INTRODUCTION}

Three-phase induction motors are responsible for more than $50 \%$ of the energy consumption in industrialized countries [1]. In recent years, most induction machine manufacturers are concerned with producing efficient motors. However, in the vast majority of applications, due to erroneous application or varying load, the motor selected is oversized for its application. In such situations the motor operates at a load condition very different from its maximum efficiency point. As an example, motors in Brazilian industrial plants operate at approximately $60 \%$ of their rated capacity [2]. Although the motor appears to be inefficient, the problem is actually due to the fact that the losses are relatively high when compared to the work being done.

The first studies for minimizing induction motor losses were based on controlling the power factor, by adjusting the stator voltage [3]. However it was soon demonstrated that the points of operation that lead to maximum efficiency or minimum input current may be very far from that for constant high power factor [4]. The problem of determining the stator voltage and frequency leading to minimal losses in induction motors has been addressed in the last three decades. The solution was described qualitatively in [5], but the nonlinearities of the machine model and saturation effects made the problem too complex for quantitative solutions without excessive simplifying assumptions [6], since the saturation effects cannot be neglected [7].

The losses minimization mechanism can be qualitatively explained as follows. In the vast majority of applications the motors operate under constant magnetic flux, even if the

Manuscript received on 12/11/2009. Revised on 15/11/2009 and $12 / 04 / 2010$. Accepted for publication on $12 / 04 / 2010$ by recommendation of the Editor Fernando L. M. Antunes. mechanical load is zero or very low. In those low load torque cases, it is obvious that the core losses could be reduced by operating under low magnetic flux. In order to improve the capacity of producing electromagnetic torque, which is needed if the load increases, the magnetic flux must be augmented. In this case, the core losses and also the copper losses due to the stator current component necessary for flux production increase. On the other hand, if the flux increases the torque producing component of the stator current is reduced and the copper losses associated with this component are lower.

Much research effort has been done in the two last decades for solving the problem of online tuning of the magnetic flux to the minimum losses value in adjustable speed drives. Some papers summarized the methods for achieving this goal in three distinct approaches [8]: a simple state controller (SSC); a loss-model-based controller (LMC); and a search controller (SC).

The SSC approaches are based on setting the displacement power factor or the rotor slip frequency. Although easy to implement, they are sensitive to flux saturation and temperature related parameter variations. The optimal control is restricted to a relatively narrow operational range. It was the only possible approach in the past, when only simple V/f drives were available.

The SC schemes provide iterative variations in the magnetic flux reference based on algorithms for tracking the minimum input power [9] [10] [11]. The SC schemes are robust to parameter variations but their precision is reduced when the flux around the minimum power is too flat. Their main drawbacks are the slow response and the fact that even when the motor operates under constant load, the SC never reaches the steady state and causes flux and torque pulsations. Further, input power measurement errors may cause oscillations around the optimum operating point or even instability.

The main advantage of the LMC methods is the use of some loss model of the induction machine, making the response fast and smooth. The main differences among the schemes proposed are on the loss model used. Many aspects like saturation, frequency or temperature affect the induction machine losses and complex precise models would of course lead to better optimization methods. Implementation of a LMC for on line determination of the magnetic flux that leads to minimum losses for each operation condition in terms of load torque and speed is a complex nonlinear problem. Due to the capacity of artificial neural networks (ANN) generalizing knowledge acquired during the learning process for implementing any mathematical function, some authors have proposed their use for maximizing efficiency in induction motor drives [12] - [13]. In [12], the measured 
speed and reference electromagnetic torque are input to an ANN previously trained for determining the $\mathrm{d}$ axis rotor current corresponding to minimum motor losses. Saturation is not taken into account and an open loop rotor flux control is implemented, since there is no rotor flux estimator. No experimental results are presented. A more complete scheme is presented in [14], in which the magnetizing inductance and rotor resistance are estimated and used together with measured speed and estimated electromagnetic torque as inputs of the ANN that determines the flux for maximum efficiency of the drive. However, the rotor flux is estimated using the induction machine stator equation (voltage model), which tends to become unstable in low speed operation. Again, no experimental results are presented. An ANN is used in [13] for obtaining the amplitude of the stator voltages for maximum efficiency in fixed speed voltage controlled induction motor drives.

In this paper neural networks are applied for determining the rotor flux vector magnitude in a direct field oriented induction motor drive, leading to operation with maximum efficiency. A rotor flux estimator based on the rotor equation (current model) that takes the magnetic saturation into consideration is used for the flux closed loop control. Simulation and experimental results demonstrate the proposed scheme performance.

\section{MODELING OF INDUCTION MACHINE WITH THE INCLUSION OF MAGNETIC SATURATION}

The most used vector equations of the induction machine model in a reference frame rotating in an arbitrary angular speed $\omega_{e}$ are [15]:

$$
\begin{gathered}
\overrightarrow{v_{s}}=R_{s} \overrightarrow{i_{s}}+\frac{d \overrightarrow{\lambda_{s}}}{d t}+j \omega_{e} \overrightarrow{\lambda_{s}}, \\
\overrightarrow{v_{r}}=\overrightarrow{0}=R_{r} \overrightarrow{i_{r}}+\frac{d \overrightarrow{\lambda_{r}}}{d t}+j\left(\omega_{e}-\omega_{r}\right) \overrightarrow{\lambda_{r}}, \\
\overrightarrow{i_{m}}=\overrightarrow{i_{s}}+\overrightarrow{i_{r}}, \\
\overrightarrow{\lambda_{s}}=\left(L_{l s}+L_{m}\right) \overrightarrow{i_{s}}+L_{m} \overrightarrow{i_{r}}, \\
\overrightarrow{\lambda_{r}}=\left(L_{l r}+L_{m}\right) \overrightarrow{i_{r}}+L_{m} \overrightarrow{i_{s}}, \\
\overrightarrow{\lambda_{m}}=L_{m} \overrightarrow{i_{m}}, \\
\frac{2}{P} J \frac{d \omega_{r}}{d t}=T_{e}-T_{c}, \\
T \frac{3}{2} \frac{P}{2}\left\{\overrightarrow{\lambda_{r}} \overrightarrow{i_{r}^{*}}\right\},
\end{gathered}
$$

where $\vec{v}, \vec{i} \mathrm{e} \vec{\lambda}$, are space vectors of voltage, current and flux, $R_{s}$ e $R_{r}$ are the resistance of stator and rotor, $L_{m}$ is the mutual inductance, $L_{l s}$ e $L_{l r}$ are leakage inductances of stator and rotor, $\omega_{r}$ is the rotor angular speed, $J$ is the drive moment of inertia, $P$ is the number of poles, $T_{c}$ and $T_{e}$ are the torque of load and electromagnetic respectively.
Models of the induction machine including the effects of magnetic saturation can be found in [16], [17], [18]. In this study, the effect of saturation is considered by updating the value of $L_{m}$ as the mutual flux varies. The values of $L_{m}$ are obtained from the magnetization curve, which is previously determined through a no-load test. Figure 1 shows the measured points and the plots of approximate functions.

The approximate function of the non-linear part of the magnetizing characteristic is:

$$
\lambda_{m}=0.55\left[1-1.7376 \exp \left(-\frac{i_{m}}{3.62}\right)\right] .
$$

The parameters of the approximate function (9) were obtained by varying them in a wide range and calculating the sum of the squared errors, comparing with the experimental points. The parameters that led to the least squared errors were then chosen.

Therefore, except for low values of $\lambda_{m},(6)$ and (9) are used to calculate $L_{m}$ :

$$
L_{m}=\left\{\begin{array}{cc}
0.062 H, & \text { if } \quad \lambda_{m} \leq 0.31 \mathrm{~Wb} \\
\frac{\lambda_{m}}{2-3.62 \ln \left(1-\frac{\lambda_{m}}{0.55}\right)}, & \text { otherwise }
\end{array}\right.
$$

\section{ROTOR FLUX ESTIMATOR CONSIDERING MAGNETIC SATURATION}

The rotor flux estimator is based on the current model:

$$
\dot{\overrightarrow{\lambda_{r}}}=\left[-\frac{1}{\tau_{r}}-j\left(\omega_{e}-\omega_{r}\right)\right] \overrightarrow{\lambda_{r}}+\frac{L_{m}}{\tau_{r}} \overrightarrow{i_{s}}
$$

Using a $d q$ reference frame oriented by the rotor angular position:

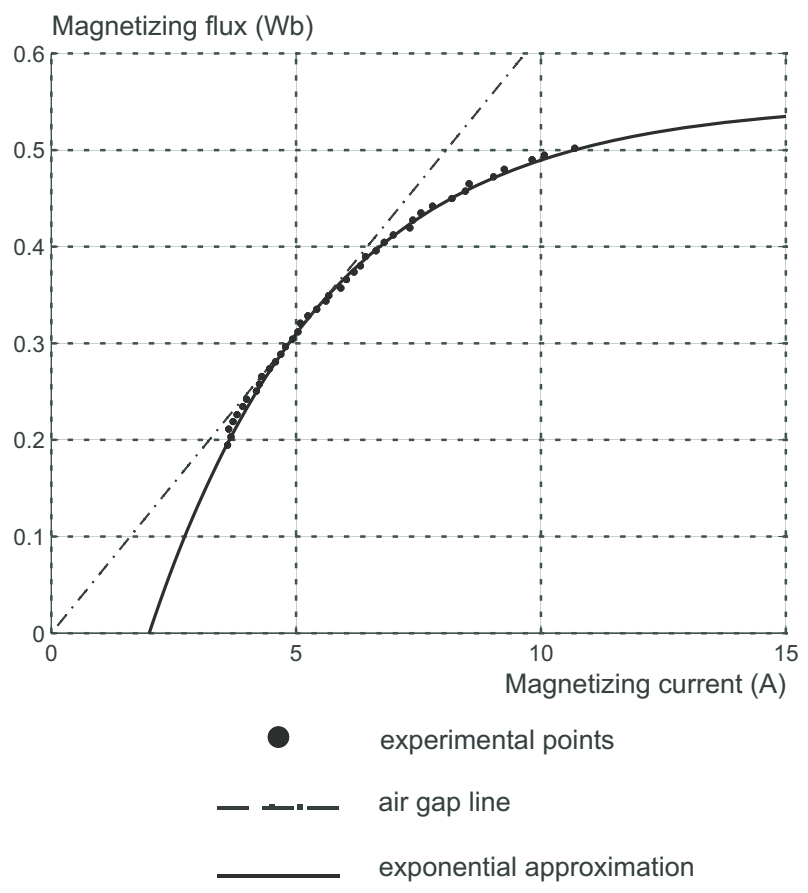

Fig. 1. No-load magnetizing characteristic 


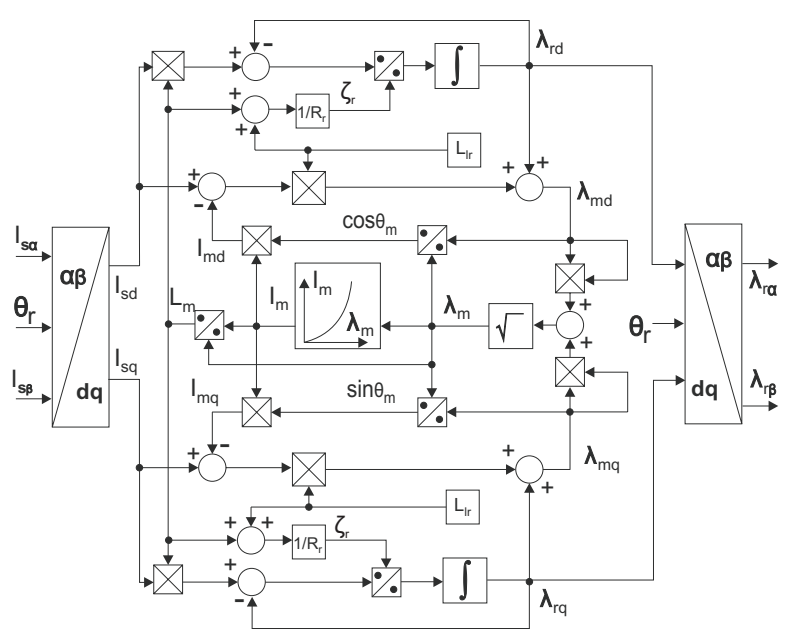

Fig. 2. Block diagram of the flux estimator including the magnetic saturation.

$$
\left\{\begin{array}{l}
\dot{\lambda_{r d}}=\frac{1}{\tau_{r}}\left(L_{m} i_{s d}-\lambda_{r d}\right) \\
\dot{\lambda_{r q}}=\frac{1}{\tau_{r}}\left(L_{m} i_{s q}-\lambda_{r q}\right) .
\end{array}\right.
$$

In the beginning of the simulation, $L_{m}$ is set equal to the non saturated mutual inductance of the machine. However, its value must be adjusted based on the magnitude of the mutual flux $\lambda_{m}$. Once the rotor flux components are obtained by solving (12), the mutual flux magnitude is calculated as follows:

$$
\left\{\begin{array}{l}
\lambda_{m d}=\lambda_{r d}-L_{l r} i_{r d}=\lambda_{r d}-L_{l r}\left(i_{m d}-i_{s d}\right) \\
\lambda_{m q}=\lambda_{r q}-L_{l r} i_{r q}=\lambda_{r q}-L_{l r}\left(i_{m q}-i_{s q}\right)
\end{array}\right.
$$

and

$$
\lambda_{m}=\sqrt{\lambda_{m d}^{2}+\lambda_{m q}^{2}} .
$$

The magnetization curve is then used for obtaining current $i_{m}$ and the mutual inductance corrected value is calculated from

$$
L_{m}=\frac{\lambda_{m}}{i_{m}} .
$$

The described flux estimation process is shown in the block diagram of Figure 2.

\section{ARTIFICIAL NEURAL NETWORKS}

The neural networks are a group of simple processing units (neurons) distributed in different layers which are able to implement any mathematic function.

These entities, after the process of adjusting their internal parameters (weights and bias), are capable of generalizing the knowledge acquired during the learning process.

Figure 3 illustrates a generic multi-layered neural network having one input layer, two hidden layers with four neurons each, and one output layer with two neurons.

The possibility of distributing the neurons in different intermediate layers, allows the solution of problems not

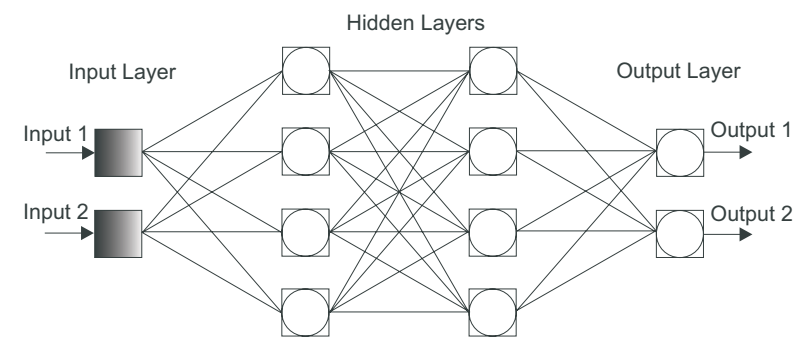

Fig. 3. A generic ANN.

linearly separable. Achievements of studies showed that an intermediate layer is sufficient to implement any continuous function [19], while two intermediate layers are sufficient to implement any mathematical function [20].

\section{THE ARTIFICIAL NEURAL NETWORKS USED}

For an ANN to perform its task satisfactorily, its input must contain information that describes the main features of the problem to be solved. For maximizing the efficiency of an induction motor, the electromagnetic torque and rotor angular speed can be used as inputs and the magnitude of the rotor flux vector as output of the ANN, as in [12] - [13].

In some previous works, ANN's were used for improving induction motor drives efficiency. In [12], an ANN with 10 neurons in the first hidden layer using a hyperbolic tangent activation function and 5 neurons in the second hidden layer with linear activation function was used. Saturation effects are neglected and the ANN output is the $d$ axis current component. Only 16 examples are used as training data. In [14] the training set is composed of 3100 examples. The ANN has 4 neurons in the input layer, 5 neurons in the first hidden layer and output the reference rotor flux.

In order to obtain the data representing the maximum efficiency conditions, simulations of the machine including the effects of magnetic saturation were performed. In these simulations, a direct rotor flux oriented vector control scheme was used for regulating the rotor speed, considering a certain load torque. The same simulation was performed for several different rotor flux magnitudes. The rotor flux magnitude that results in minimum input power is the optimum flux in terms of machine efficiency, since that torque and speed conditions are attended with minimum input power. The same procedure was repeated for determining the optimal flux value for several pairs of torque and speed. Table I shows the range of variation of torque, speed and flux used to construct the ANN training database. The base values used in the representation in pu are $w_{r b}=340$ elect.rad $/ \mathrm{s}, T_{e b}=20 \mathrm{Nm}$ e $F_{i r b}=0.425 \mathrm{~Wb}$. The database set is then composed of 420 points. Figure 4 presents the optimum flux surface obtained.

The representation and choice of the ANN was made following the recommendations of the Proben Report [21]. If only one ANN was used to represent the entire optimum surface, it would require a lot of neurons in each hidden layer. Consequently, the computational burden for running the ANN each sampling period would be very high. In order to reduce the computational effort for implementing the ANN, in terms of memory required and processing time, the induction motor 
TABLE I

Limits of the database

\begin{tabular}{ccc}
\hline Variable & Interval [pu] & Increment [pu] \\
\hline Speed & $0.05 \mathrm{a} 1$ & 0.05 \\
\hline Torque & $0 \mathrm{a} 1$ & 0.05 \\
\hline Flux & $0.1 \mathrm{a} 1.175$ & 0.025 \\
\hline
\end{tabular}

TABLE II

Artificial neural network versus operating range

\begin{tabular}{cc}
\hline ANN & Load Torque $[\mathrm{pu}]$ \\
\hline 1 & 0 a 0.1 \\
\hline 2 & 0.1 a 0.2 \\
\hline$\vdots$ & $\vdots$ \\
\hline 10 & 0.9 a 1.0 \\
\hline
\end{tabular}

operating range was divided in ten regions, according to the load torque. One ANN with small structure, and therefore low computational burden, was then constructed for each load torque region as described in Table II. The electromagnetic torque estimated using the estimated rotor flux is then used for choosing which ANN must be run each sampling period.

In order to avoid any neuron to operate in the saturation region, where the output values are close to the upper and lower limits of the activation functions, the database set was normalized.

Since the input values (speed and torque) are in the range $[0,1]$, they do not need to be normalized. However, the ANN output, the reference magnitude of the rotor flux vector, vary in the interval [0.1,1.175] and was normalized using 0.2 and 0.8 as lower and upper limits of the normalization interval, respectively. The normalizing and de-normalizing equations of the ANN output are then:

$$
\begin{gathered}
x_{n i j}=\frac{0.155+0.6 x_{i j}}{1.075} \\
x_{i j}=\frac{-0.155+1.075 x_{n i j}}{0.6}
\end{gathered}
$$

The data used for performing benchmarks on neural network learning algorithms were split into three parts: one set on which the training is performed, called the training set;

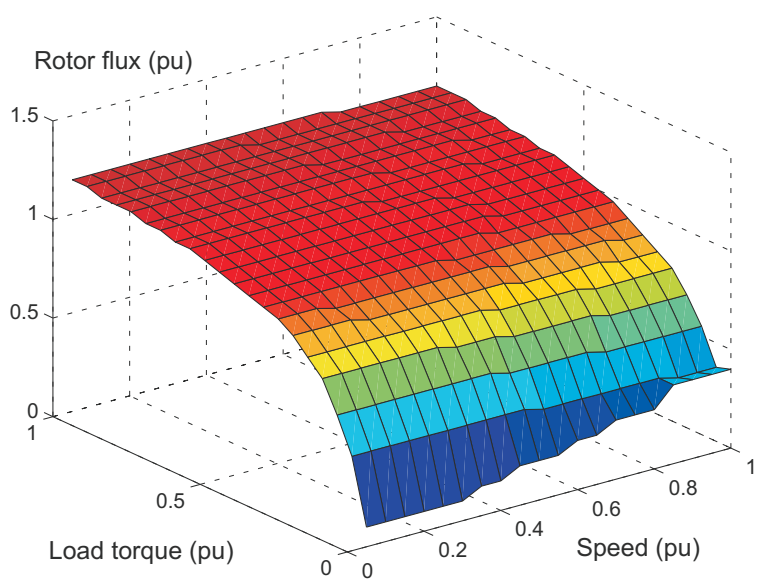

Fig. 4. Database optimum surface. a validation set used as a pseudo test set in order to evaluate the quality of a network during training, and another part on which the performance of the resulting network is measured, called the test set. The database was divided in training, validation and test subsets, obeying the proportions of $70 \%, 20 \%$ and $10 \%$ respectively [21].

All the networks used in this study have the multilayer perceptron (MLP) architecture and are trained using Matlab [22]. The learning algorithm used was the LevenbergMarquardt [23]. All networks have one input layer, one or two hidden layers and one output layer. The number of neurons in the hidden layers vary between two and eight and the activation function applied in these layers is a hyperbolic tangent or logistic sigmoid. Since the output values of the database are always positive, the activation function used in the output layers was the sigmoid logistics.

Table III shows the architectures of the ten neural networks after training. The surface generated by the neural networks, considering many input pairs of speed and torque is illustrated in Figure 5.

\section{SIMULATION RESULTS}

Some simulations were performed for evaluating the algorithm ability to select the flux corresponding to maximum efficiency. The simulation program contains the usual induction machine model. However, after calculating the rotor flux, (13) is used for computing the magnetizing flux and the mutual inductance is corrected through applying (10), including the effects of magnetic saturation. The rotor speed control is performed, as in usual drives using field oriented control, by a PI controller, whose output is the $q$ axis component reference current. However, the flux reference is set by the ANN for achieving maximum efficiency. The described flux observer is used to determine the magnitude and position of the rotor flux vector from the measured stator currents and rotor speed. The calculated flux magnitude and the $q$ axis current component transformed to the flux oriented reference frame, are used to obtain the estimated electromagnetic torque. This estimated torque is then used for selecting which ANN must be used. The estimated torque and the measured rotor speed are then input to the selected ANN for obtaining the reference optimum rotor flux magnitude. The difference between the reference and observed flux magnitude is input to a PI controller that outputs the $d$ axis component reference current. The stator currents are also regulated using PI controllers. A vector PWM scheme is then applied for imposing the duty cycles necessary to produce the reference voltages determined by the current controllers. Figure 6 shows the direct field oriented control block diagram including the neural network.

Two other simulation programs were used for evaluating the proposed scheme. In the first one, the rotor flux magnitude reference was maintained equal the rated value and no losses minimization process was applied. In the second case, the ANN was substituted by an ideal reference flux calculator, which uses the training database for obtaining the optimum flux magnitude.

Figures 7-9 show the relation between average input 
TABLE III

Summary of networks architectures

\begin{tabular}{cccc}
\hline ANN & $\begin{array}{c}\text { Load Torque } \\
\text { Range }(\mathbf{p u})\end{array}$ & $\begin{array}{c}\text { Hidden } \\
\text { Neurons }\end{array}$ & $\begin{array}{c}\text { Activation } \\
\text { Functions }\end{array}$ \\
\hline 1 & {$[0 ; 0,1)$} & $3-3$ & tansig-tansig \\
\hline 2 & {$[0,1 ; 0,2]$} & $4-2$ & tansig-tansig \\
\hline 3 & $(0,2 ; 0,3]$ & $4-2$ & tansig-tansig \\
\hline 4 & $(0,3 ; 0,4)$ & $3-4$ & tansig-logsig \\
\hline 5 & {$[0,4 ; 0,5]$} & $1-6$ & tansig-tansig \\
\hline 6 & $(0,5 ; 0,6)$ & $3-2$ & tansig-logsig \\
\hline 7 & {$[0,6 ; 0,7]$} & $2-5$ & tansig-logsig \\
\hline 8 & $(0,7 ; 0,8)$ & $3-2$ & tansig-logsig \\
\hline 9 & {$[0,8 ; 0,9)$} & $4-4$ & tansig-logsig \\
\hline 10 & {$[0,9 ; 1,0]$} & $3-3$ & tansig-logsig \\
\hline
\end{tabular}

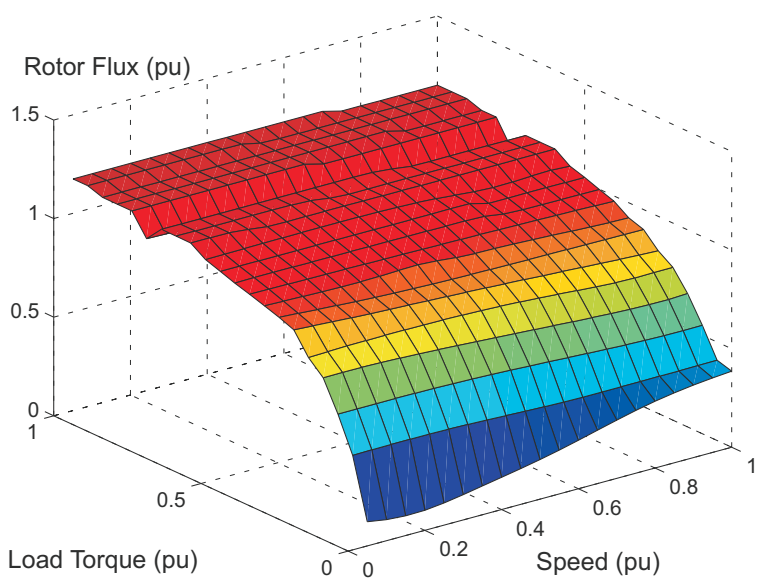

Fig. 5. Surface generated by neural networks.

power $\left(P_{\text {input }}\right)$ and average input power when the flux is maintained in the rated value $\left(P_{\text {rated }}\right.$ flux $)$ in the three simulated conditions:

1. Ideal reference flux calculator;

2. Reference flux set at nominal value (control with no losses minimization algorithm);

3. Reference flux provided by the ANN.

From the simulation results it can be concluded that with low load, significant reduction on the input power can be achieved if the reference flux is reduced. However, almost no losses reduction is possible if the motor operates with approximately one half of the rated load. Losses reduction is also possible if the motor is heavily loaded, by increasing the rotor flux magnitude somewhat above the rated value.

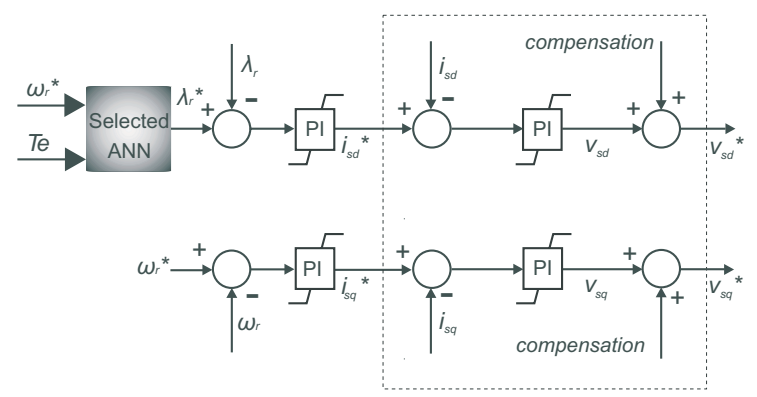

Fig. 6. Direct field oriented control block diagram including the neural network.

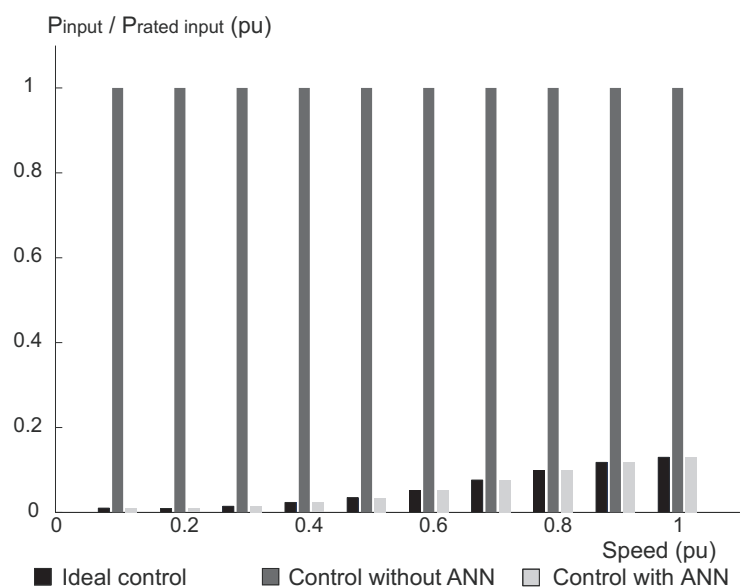

Fig. 7. Simulation results. Input power comparison at no-load operation.

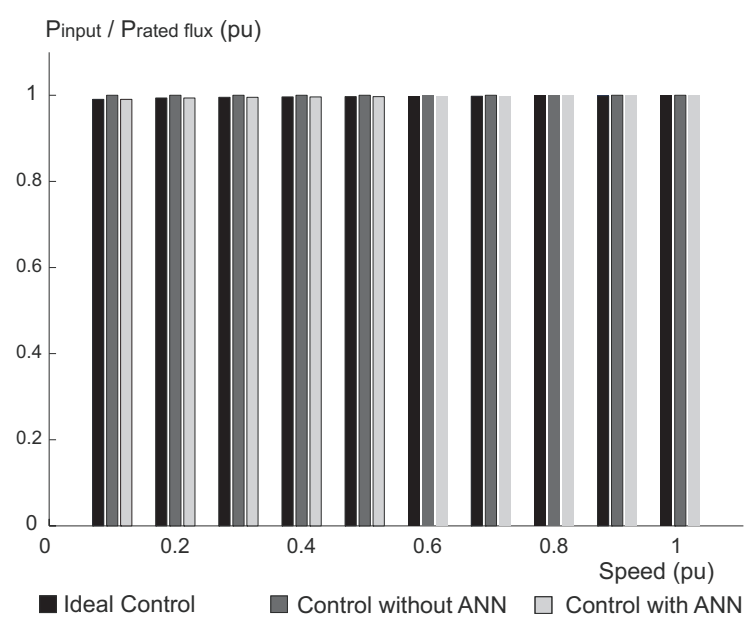

Fig. 8. Simulation results. Input power comparison for a load torque equal to 0.5 p.u.

\section{EXPERIMENTAL RESULTS}

The proposed scheme was validated using the experimental setup shown in Figure 10. This system consists of five parts: an induction motor to be controlled, a dc machine used to impose the load torque, a frequency converter, a discrete-time control platform and a PWM interface. The control platform contains circuits for conditioning the signals to be sent to an acquisition board installed in a PC microcomputer. The PC computer processes the control algorithm for determining the motor stator voltage references. These voltages are then used for computing the switches duty cycles, which are sent to dedicated PWM interfaces responsible for producing the switches command signals. The parameters of the induction motor were obtained from conventional no-load and blocked rotor tests and are shown the Table V.

The control system performance during load torque disturbances was verified by applying and removing the load torque every three seconds approximately. The drive behavior with and without using the maximum efficiency scheme are compared. In Figures $11-13$ the plots of estimated rotor flux magnitude, rotor speed, estimated and reference 
TABLE IV

Induction motor parameters

\begin{tabular}{ccc}
\hline Power $=5 \mathrm{hp}$ & $V_{s}=380 \mathrm{~V}$ & $I_{s}=8.16 \mathrm{~A}$ \\
\hline$P=4$ poles & 3 phases & $f=60 \mathrm{~Hz}$ \\
\hline$\omega_{r}=1715 \mathrm{rpm}$ & $L_{l s}=5.44 \mathrm{mH}$ & $L_{l r}=5.44 \mathrm{mH}$ \\
\hline$J=0.10 \mathrm{kgm}^{2}$ & $R_{s}=0.53 \Omega$ & $R_{r}=0.75 \Omega$ \\
\hline
\end{tabular}

electromagnetic torque, input power, $d$ and $q$ reference and measured stator current components are presented for both control strategies. The reference speed is maintained equal to 204 elect.rad/s. As expected, the input power is lower when the ANN is used. Since in the first seconds of simulation the load corresponds only to friction and wind losses, the magnetic flux for maximum efficiency is reduced. Consequently, the electromagnetic torque production capability is reduced during this period and control performance after load variation is somewhat worse. It can also be observed that bigger power reduction is achieved at low load operation, confirming the simulations results. Also, as expected, the $d$ axis current variation is observed only when the ANN is used. In this case, since the rotor flux is reduced, bigger variations occur in the $q$ axis current. It should be noted that the control performance reduction is not expected to happen in cases where the reference flux output from the ANN is equal or higher than the rated value since, in those cases, the maximum electromagnetic torque is not reduced. Figures 14 - 16 present experimental results for such a case. In fact a better speed control performance is observed since the magnetic flux is set a little above the rated value. However, since the machine operates closer to the nominal values, the relative power reduction is smaller than that for low load operation.

The ability of the proposed scheme of maximizing the drive efficiency was experimentally verified through no-load tests in several angular speeds and also for different load torque conditions. The induction machine speed was first controlled with no mechanical load applied, with and without the use of the ANN, and the respective measured input powers are compared in Table VI. As expected, a significant power reduction is observed. In other experiments, the drive is used for controlling the rotor speed at 272rad.ele/s and different load torques are applied. Table VII presents a comparison of the drive input powers with and without using the maximum efficiency scheme. Again, significant efficiency improvement is achieved for low load torque operation. However, the power consumption is almost the same for cases when the rotor flux set by the ANN is near to the rated value.

\section{CONCLUSION}

This paper presents the use of ANN as a component of a field oriented induction motor drive for maximizing the system efficiency. In order to obtain accurate results, a flux observer considering the effects of magnetic saturation is implemented. This is necessary because depending on the load torque and rotor speed, the flux magnitude for maximum efficiency reaches values in the saturated region of the magnetization curve.

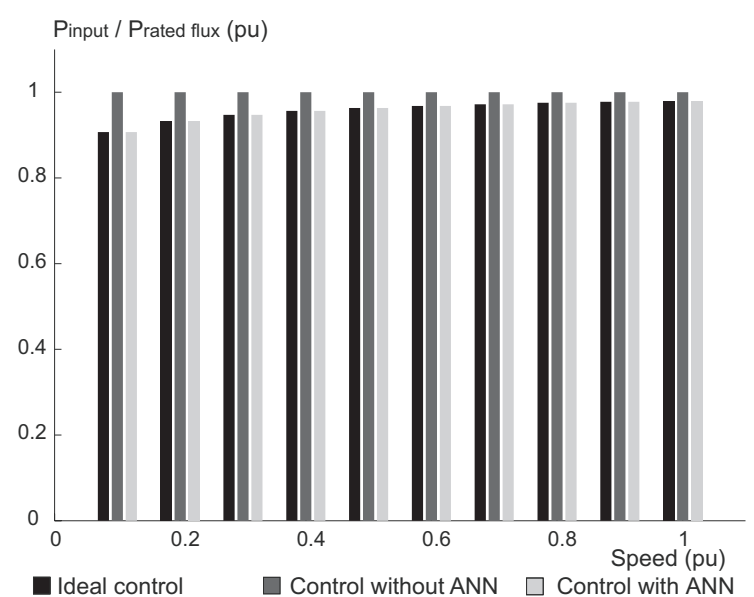

Fig. 9. Simulation results: input power comparison at full-load operation.

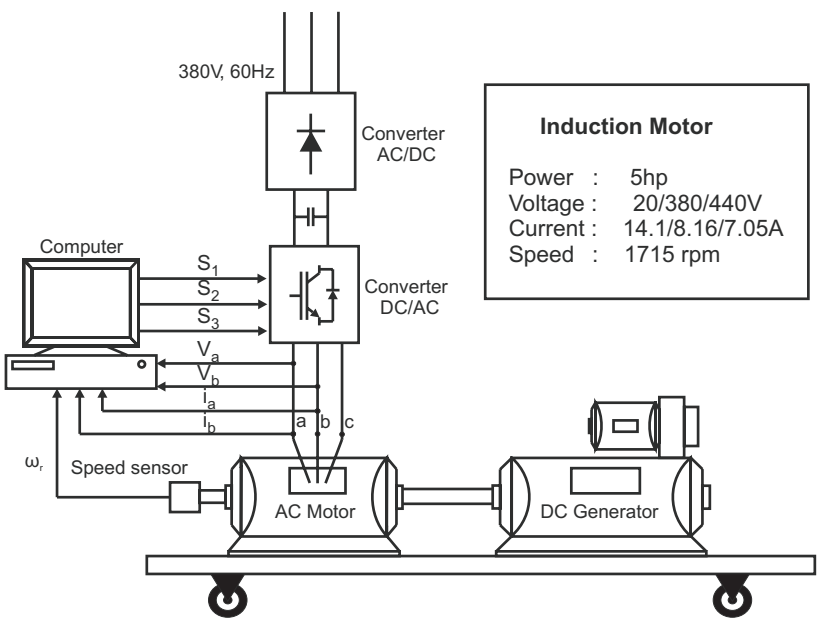

Fig. 10. Structure of the system.

TABLE V

Induction motor parameters

\begin{tabular}{ccc}
\hline Power $=5 \mathrm{hp}$ & $V_{s}=380 \mathrm{~V}$ & $I_{s}=8.16 \mathrm{~A}$ \\
\hline$P=4$ poles & 3 phases & $f=60 \mathrm{~Hz}$ \\
\hline$\omega_{r}=1715 \mathrm{rpm}$ & $L_{l s}=5.44 \mathrm{mH}$ & $L_{l r}=5.44 \mathrm{mH}$ \\
\hline$J=0.10 \mathrm{kgm}^{2}$ & $R_{s}=0.53 \Omega$ & $R_{r}=0.75 \Omega$ \\
\hline
\end{tabular}

TABLE VI

Input power reduction experiment at no-load and several angular speeds

\begin{tabular}{|c|c|c|c|}
\hline $\begin{array}{c}\omega_{r} * \\
(\text { elect.rad/s) }\end{array}$ & $P_{W O A N N}(W)$ & $P_{W A N N}(W)$ & $\begin{array}{c}\text { Power } \\
\text { Reduction }(\%)\end{array}$ \\
\hline 34.0000 & 335.0130 & 124.2832 & 62.9020 \\
\hline 68.0000 & 354.7379 & 156.0212 & 56.0179 \\
\hline 102.0000 & 372.4988 & 178.1349 & 52.1784 \\
\hline 136.0000 & 375.9838 & 188.0748 & 49.9780 \\
\hline 170.0000 & 392.9030 & 204.9831 & 47.8286 \\
\hline 204.0000 & 402.7912 & 214.4312 & 46.7637 \\
\hline 238.0000 & 409.3746 & 235.7592 & 42.4099 \\
\hline 272.0000 & 414.2416 & 259.9184 & 37.2544 \\
\hline 306.0000 & 419.1219 & 285.9092 & 31.7838 \\
\hline 340.0000 & 423.3273 & 318.5470 & 24.7516 \\
\hline
\end{tabular}



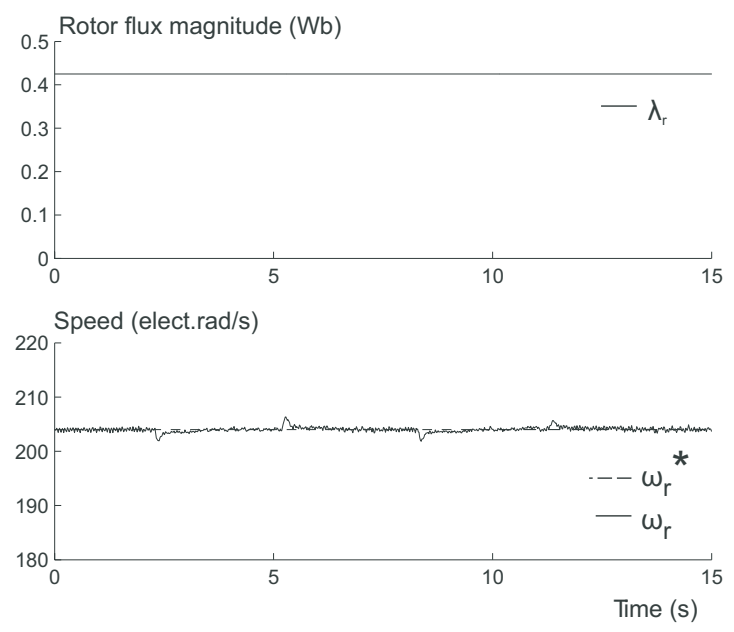

(a)
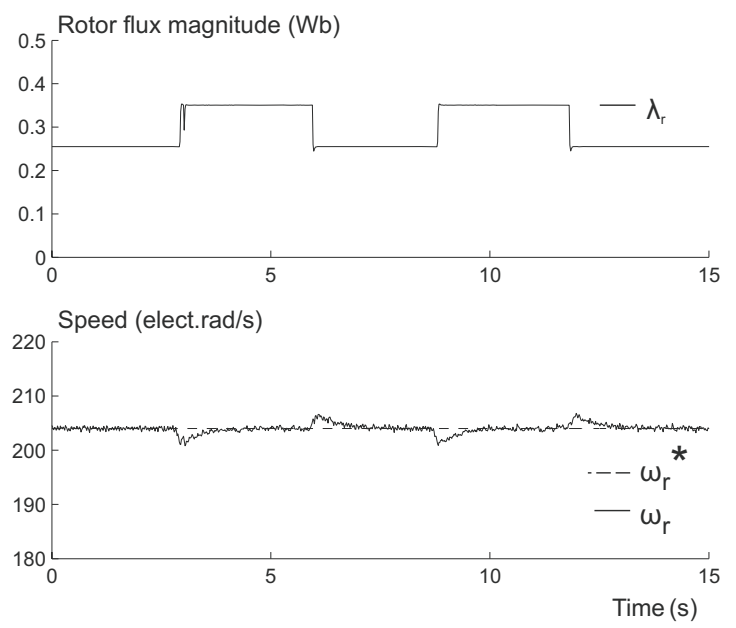

(b)

Fig. 11. Experimental results. Flux and speed responses to load torque steps. $\omega_{r} *=204$ elect.rad/s: (a) without neural network; (b) with neural network.
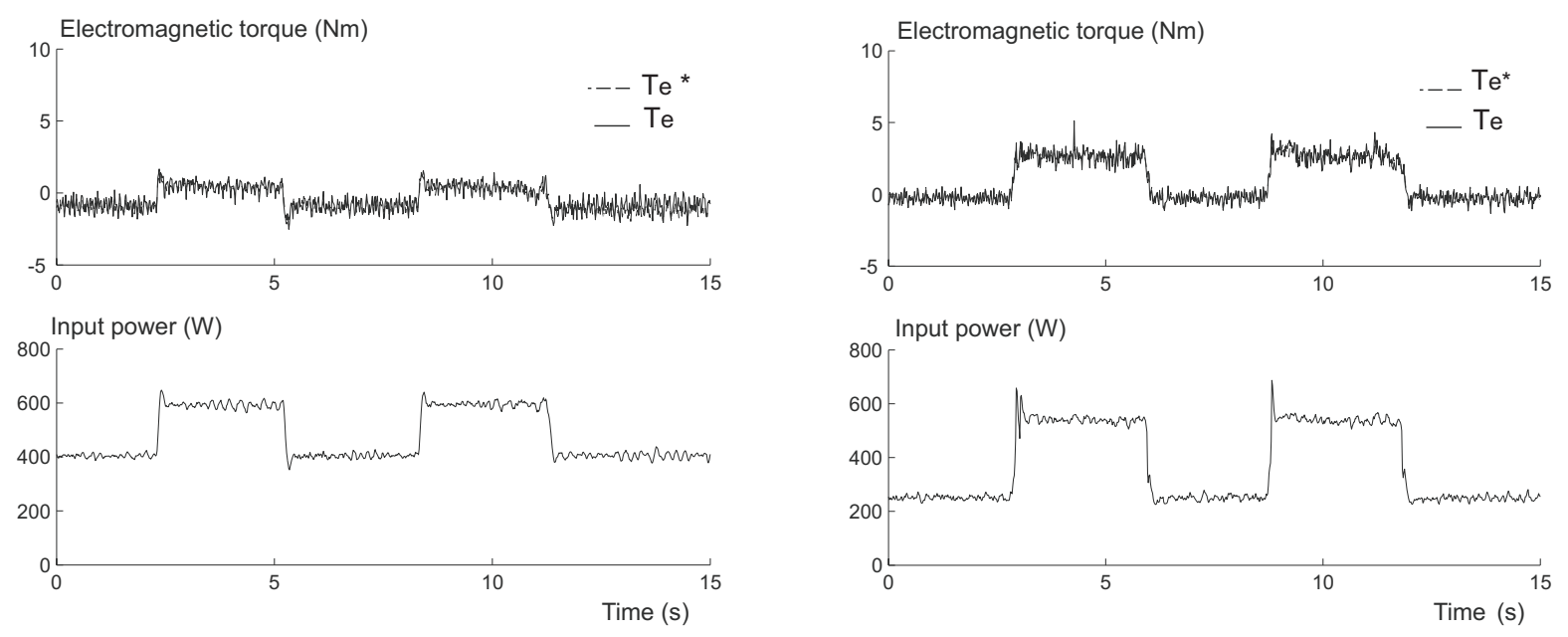

(a)

(b)

Fig. 12. Experimental results. Electromagnetic torque and active power responses to load torque steps. $\omega_{r} *=204$ elect.rad/s: (a) without neural network; (b) with neural network.
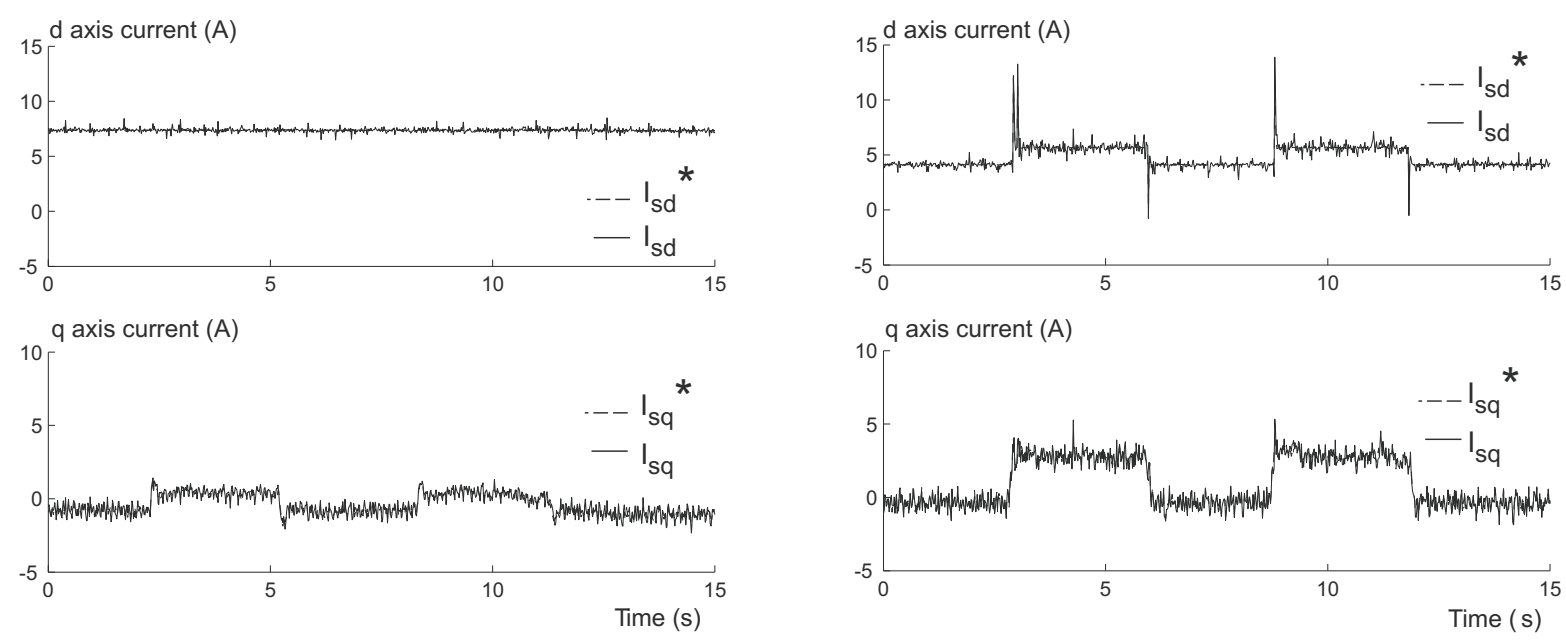

(a)

(b)

Fig. 13. Experimental results. Flux and torque current components during load torque steps. $\omega_{r} *=204$ elect.rad/s: (a) without neural network; (b) with neural network. 

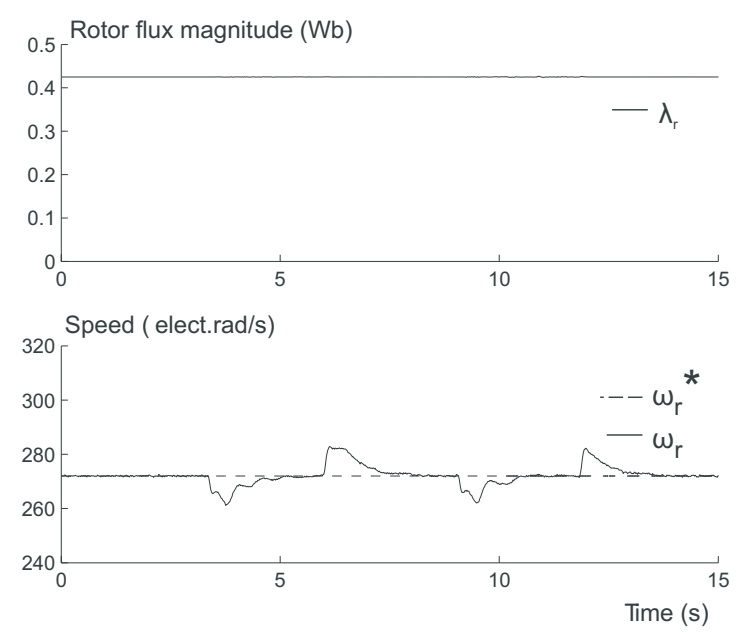

(a)
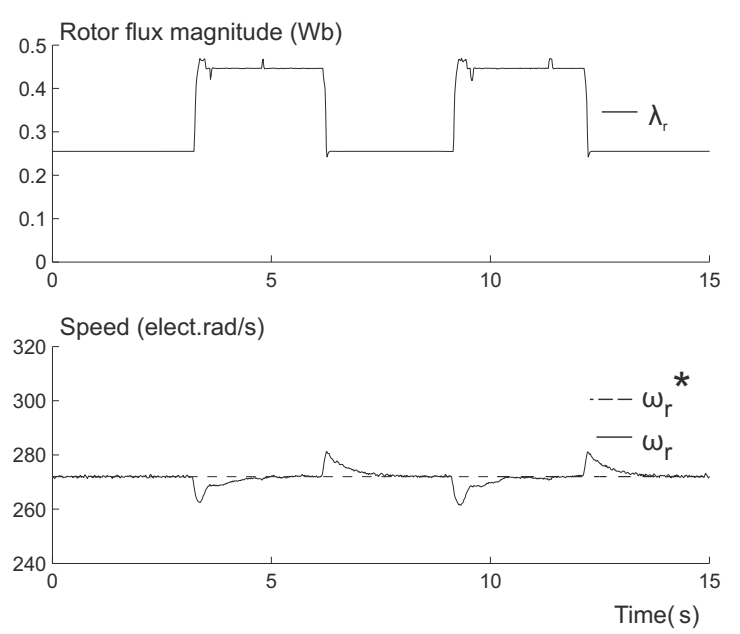

(b)

Fig. 14. Experimental results. Flux and speed responses to load torque steps. $\omega_{r} *=272$ elect.rad/s: (a) without neural network; (b) with neural network.
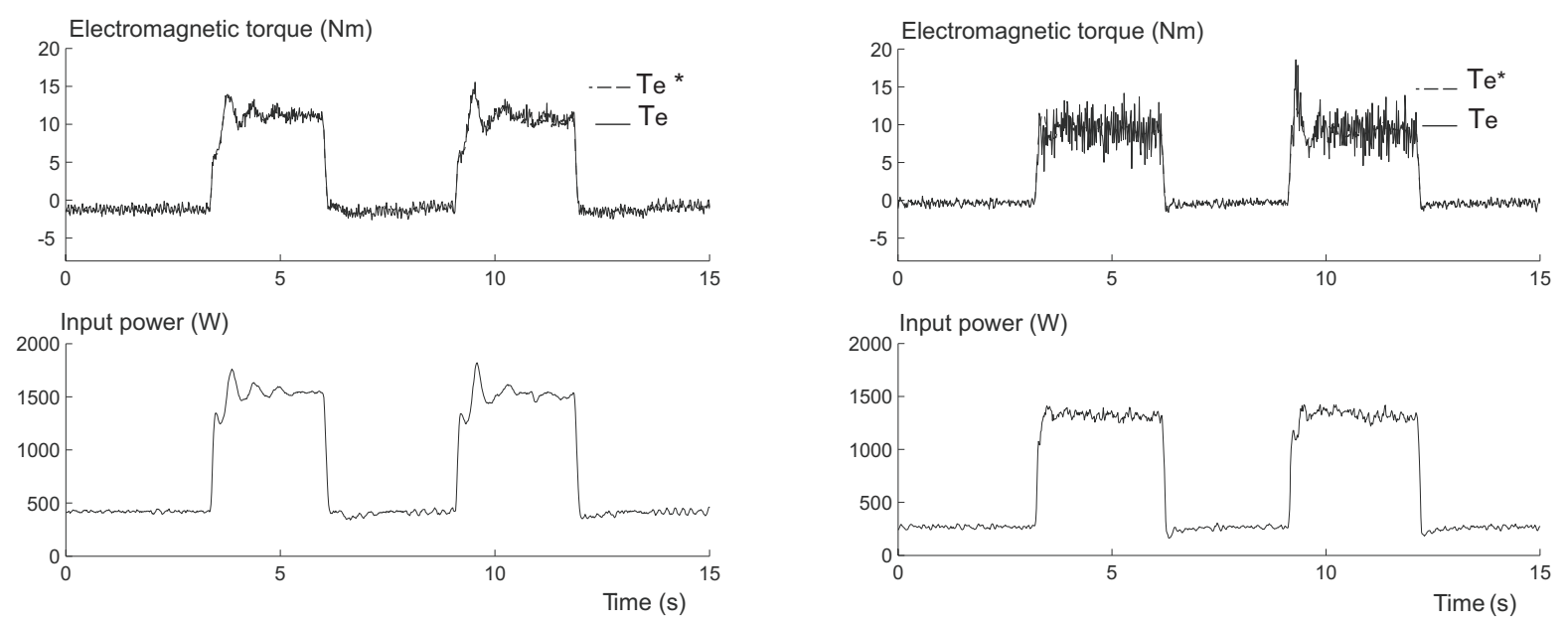

(a)

(b)

Fig. 15. Experimental results. Electromagnetic torque and active power responses to load torque steps. $\omega_{r} *=272$ elect.rad/s: (a) without neural network; (b) with neural network.
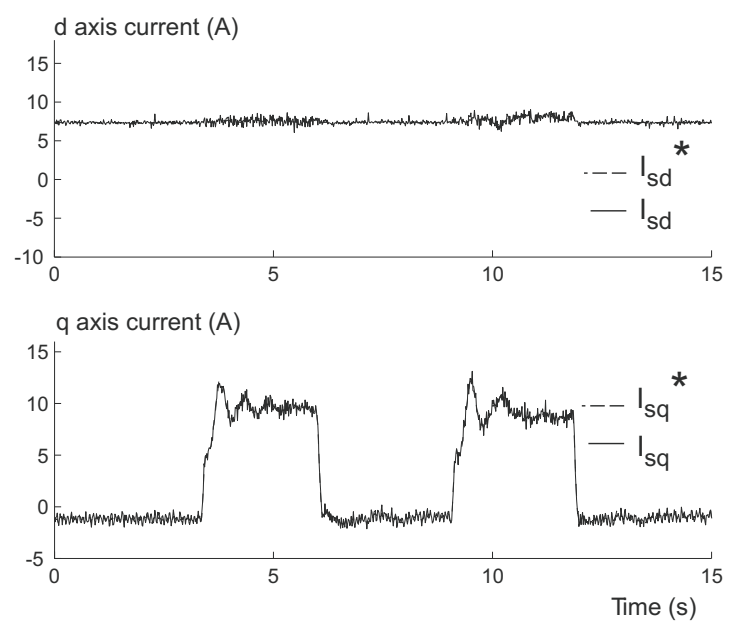

(a)
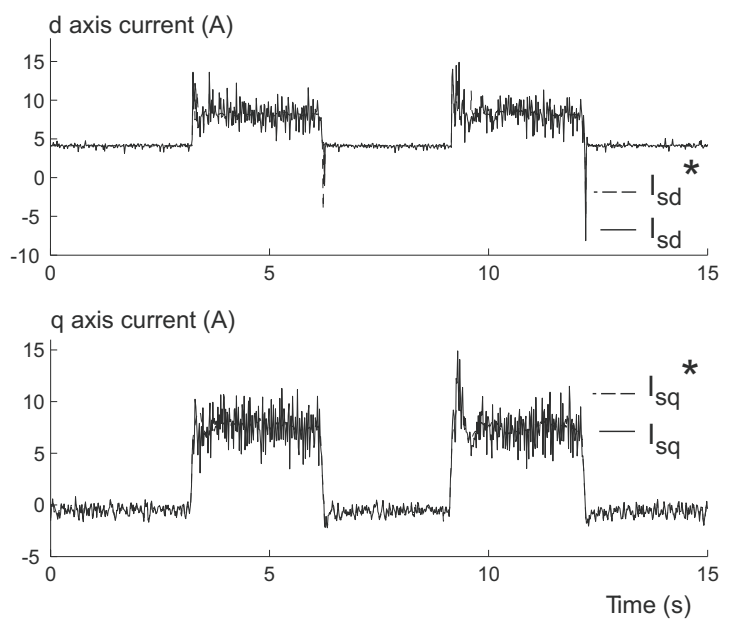

(b)

Fig. 16. Experimental results. Flux and speed responses to load torque steps. $\omega_{r} *=272$ elect.rad/s: (a) without neural network; (b) with neural network. 
TABLE VII

Input power reduction experiment at fixed angular speed and variable load torque

\begin{tabular}{cccc}
\hline $\begin{array}{c}\omega_{r} * \\
\text { (elect.rad/s) }\end{array}$ & $P_{W O A N N}(W)$ & $P_{W A N N}(W)$ & $\begin{array}{c}\text { Power } \\
\text { Reduction (\%) }\end{array}$ \\
\hline 272,0000 & 479,1414 & 365,1314 & $\mathbf{2 3 , 7 9 4 6}$ \\
\hline 272,0000 & 498,2382 & 402,2270 & $\mathbf{1 9 , 2 7 0 1}$ \\
\hline 272,0000 & 507,8761 & 408,8983 & $\mathbf{1 9 , 4 8 8 6}$ \\
\hline 272,0000 & 545,0132 & 466,6384 & $\mathbf{1 4 , 3 8 0 3}$ \\
\hline 272,0000 & 636,7167 & 583,2245 & $\mathbf{8 , 4 0 1 3}$ \\
\hline 272,0000 & 824,4775 & 831,7987 & 0,8880 \\
\hline 272,0000 & 877,7757 & 884,9593 & 0,8184 \\
\hline 272,0000 & 930,6873 & 942,6043 & 1,2805 \\
\hline 272,0000 & 1086,7428 & 1043,5501 & $\mathbf{3 , 9 7 4 5}$ \\
\hline \multicolumn{4}{c}{$P_{W O A N N}$ Input power - control without ANN } \\
$P_{W A N N}$ Input power - control with ANN \\
\hline
\end{tabular}

The results presented show that the losses reduction achieved by adjusting the rotor flux is more evident in low load operation. In these cases, the induction motor operates with rotor flux below the rated value. As a consequence, the maximum electromagnetic torque is reduced. Nevertheless, the dynamic performance of the drive with the optimum efficiency scheme is not severely affected and can be acceptable in most practical cases.

It is worth noting that in the proposed method the ANN is trained offline, before operation. Therefore, parameter deviations might affect the performance of the scheme for maximizing the motor efficiency. Some tests for evaluating this drawback and a correction scheme are under investigation.

\section{REFERENCES}

[1] Energy efficiency - the role of power electronics. In European Workshop on Energy Efficiency - the Role of Power Electronics, 2007.

[2] W. R. Araujo, L. C. Leite, S. G. Moreira, V. M. Pereira, and A. R. da Silva Junior. Aplicação de técnicas de inteligência artificial visando eficiência energética e estimação de parâmetros em sistemas motrizes industriais. Eletrônica de Potência, 13(4):209_ 216, November 2008.

[3] T. W. Jian, D. W. Novotny, and N. L. Schmitz. Characteristic induction motor slip values for variable voltage part load performance optimization. IEEE Trans. Power App. Syst., (1):38-46, Jan./Feb. 1983.

[4] T. M. Rowan and T. A. Lipo. A quantitative analysis of induction motor performance improvement by scr voltage control. In IEEE PESC, pages 312-321, 1982.

[5] A. Kusko and D. Galler. Control means for minimization of losses in ac and dc motor drives. IEEE Trans. Ind. Appl., (4):561-570, Jul./Aug. 1983.

[6] J. M. D. Murphy and V. B. Honsinger. Efficiency optimization of inverter-fed induction motor drives. In IEEE IAS, pages 544-552, 1982.

[7] D. S. Kirschen, D. W. Novotny, and W. Suwanwisoot. Minimizing induction motor losses by excitation control in variable frequency drives. IEEE Trans. Ind. Appl., (5):1244-1250, Sep./Oct. 1984.

[8] S. N. Vulosavic and E. Levi. Robust dsp-based efficiency optimization of a variable speed induction motor drive.
IEEE Trans. Ind. Electron., 50(3):560-570, May/Jun. 2003.

[9] D. S. Kirschen, D. W. Novotny, and T. A. Lipo. On line efficiency optimization of a variable frequency inductionmotor drive. IEEE Trans. Ind. Appl., (4):610-616, Jul./Aug. 1985.

[10] I. Kioskeridis and N. Margaris. Loss minimization in scalar-controlled induction motor drives with search controllers. IEEE Trans. Power Electron., 11(2):213220, March 1996.

[11] J. M. Moreno-Eguilaz, M. Cipolla, J. Peracaula, and P. J. da Costa Branco. Induction motor optimum flux search algorithms with transient state loss minimization using a fuzzy logic based supervisor. In IEEE PESC, pages 1302-1308, 1997.

[12] K. M. Hasan, L. Zhang, and B. Singh. Neural network control of induction motor drives for energy efficiency and high dynamic performance. In Conf. Ind. Electron. Control Instr., 1997.

[13] K. Sundareswaran and S. Palani. Artificial neural network based voltage controller for energy efficient induction motor drive. In IEEE Conf. Global Connect. Energy Computer Commun. Control, 2006.

[14] G. M. Aguilar, J. M. M. Eguilaz, B. Pryymak, and J. Peracaula. A neural network based optimal rotor flux estimator for efficiency optimization an induction motor drive. In IEEE ISIE, 2006.

[15] D. W. Novotny and T. A. Lipo. Vector control and dynamics of ac drives. In Oxford University Press Inc., 1996.

[16] J. O. Ojo, A. Consoli, and T. A. Lipo. An improved model of saturated induction machines. IEEE Trans. Ind. Appl., 26(2):212-221, Mar./Apr. 1990.

[17] J. C. Moreira and T. A. Lipo. Modeling of saturated ac machines including air gap flux harmonic components. IEEE Trans. Ind. Appl., 28(2):343-349, Mar./Apr. 1992.

[18] P. Ljusev, G. Stumberger, and D. Dolinar. Rotor flux linkage oriented control of induction motor with included magnetic saturation. IEE Electric Power Appl., 152(1):112-118, Jan. 2005.

[19] G. Cybenko. Continuos valued neural networks with two hidden layers are sufficient. In Tufts University, Technical report, 1988.

[20] G. Cybenko. Approximation by superpositions of a sigmoid function. Mathematics of Control, Signals and Systems, 2:303-314, 1989.

[21] L. Prechelt. Proben1 - a set of neural network benchmark problems and benchmarking rules. In Universit at Karlsruhe, Germany, 1994.

[22] Getting started with matlab. In R2006b ed., The Math Works, 2006.

[23] D. Marquardt. An algorithm for least-squares estimation of nonlinear parameters. J. Appl. Math. SIAM, 11:431$441,1963$.

\section{BIOGRAPHIES}

Arineu F. dos Santos was born in Recife, Brazil, in 1983. $\mathrm{He}$ received the B.S. and the M.S. degrees in electrical 
engineering from the Federal University of Pernambuco, Recife, Brazil, in 2006 and 2008, respectively.

Since 2009 he is with the Department Service of Distribution of the Eletrobras Distribuio Piaui, Brazil. His research interests are artificial neural networks and electrical systems efficiency maximization.

Francisco A. S. Neves was born in Campina Grande, Brazil, in 1963. He received the B.S. and M.Sc. degrees in electrical engineering from the Federal University of Pernambuco, Recife, Brazil, in 1984 and 1992, respectively, and the Ph.D. degree in electrical engineering from the Federal University of Minas Gerais, Belo Horizonte, Brazil, in 1999.

He worked as a visiting scholar at Georgia Institute of Technology - USA, during 1999, and at Alcala University - Spain, from Feb/2008 to Jan/2009. Since 1993, he has been with the Department of Electrical Engineering, Federal University of Pernambuco, where he is currently a Professor of Electrical Engineering. His research interests include power electronics, renewable energy systems, power quality and grid synchronization methods.

Ronaldo R. B. de Aquino was born in Recife, Brazil, in
1962. He received the B.S. and M.Sc. degrees in electrical engineering from the Federal University of Pernambuco (UFPE), Brazil, in 1983 and 1995, respectively, and the D.Sc. degree from the Federal University of Paraiba (UFPB), Brazil, in 2001 .

Since 1995 he has been with the Federal University of Pernambuco (UFPE), where he is a full professor of the Electrical Engineering Department. His research interests concerns to applications of artificial intelligence tools, especially artificial neural networks, to load and wind forecasting, economic load dispatch, control systems, energy efficiency, power transformer and insulators diagnosis.

Marcelo C. Cavalcanti was born in Recife, Brazil, in 1972. He received the B.S. degree in electrical engineering in 1997 from the Federal University of Pernambuco, Recife, Brazil, and the M.S. and Ph.D. degrees in electrical engineering from the Federal University of Campina Grande, Campina Grande, Brazil, in 1999 and 2003, respectively. Since 2003, he has been at the Department of Electrical Engineering, Federal University of Pernambuco, where he is currently a Professor of Electrical Engineering. His research interests are renewable systems, power quality and three-phase matrix converters. 